\title{
Priorities and Strategies to Boost Incomes of Marine Fisher Folk in India
}

\author{
Shinoj Parappurathu*, Grinson George, R. Narayanakumar, N. Aswathy, \\ C. Ramachandran and A. Gopalakrishnan
}

ICAR-Central Marine Fisheries Research Institute, Kochi-682 018, Kerala

\begin{abstract}
This paper presents a set of alternative strategies and options for enhancing the incomes of India's coastal fisher folk. Several options such as sustainable exploitation of deep sea and non-conventional resources, improving the efficiency of fishing through modernization/technological up-gradation of fishing fleet/ gears, harnessing the potential of space and information communication technologies (ICT), intensification of mariculture, and strengthening fish value chains are discussed. The paper underlines that a thriving coastal fishery economy is necessary to meet the future demand for fish and fishery products in the country.
\end{abstract}

Key words: Marine fisheries; mariculture; technological innovation; institutional reforms.

JEL Classification: Q22; O47; O43

\section{Introduction}

India is endowed with a rich marine fishery resource-base, comprising a coast line of about 8,118 $\mathrm{km}$ encompassing an exclusive economic zone (EEZ) of 2.025 million sq. $\mathrm{km}$, apart from a continental shelf area of nearly 0.53 million sq. $\mathrm{km}$. The sector has exhibited an impressive performance during the past six decades with over six-times increase in landings from a meager 0.53 million tonnes (Mt) in 1950-51 to 3.63 Mt in 2016 (CMFRI, 2017). Such a feat was achieved with gradual enhancements in the size of fishing fleet, technological up-gradation of fishing vessels, introduction of efficient fishing gears, development of landing centres, strengthening of value chains through establishment of a network of wholesale and retail markets, and so on. Presently, the marine fishing sector in the country is operating at a level which is close to its total estimated potential of 4.41 Mt, comprising 47 per cent demersal, 48 per cent

\footnotetext{
* Author for correspondence

Email: pshinoj@gmail.com
}

pelagic and 5 per cent oceanic resource groups (DADF, 2011). However, marine aquaculture (mariculture) is emerging as a prominent source of future fish production in India. Gentry et al., 2017 have pegged India's fish production potential through mariculture to be $4.53 \mathrm{Mt}$, assuming that one per cent of suitable area is developed for low-density marine fin-fish aquaculture. The total fish production potential in India's EEZ therefore comes close to $9 \mathrm{Mt}$, thereby offering promising opportunities to be harnessed.

In spite of remarkable growth performance and promising future potential, the marine fisheries sector in India faces several challenges. The technological changes in the realms of vessel propulsion and designs, engine power, gear designs and capture methods over a very short span of time, especially after mid-1980s, have resulted in a sea change in the sector with significant impacts on the lives of people depending on it. One of the major consequences has been the emergence of a harbour-based trawler fishing industry, parallel to a very sizeable small-scale subsector along 
the beaches that resulted in frequent conflicts and consequent social tensions (Bavinck and Johnson, 2008). Intense competition for resources in an openaccess, multi-gear, multi-species context subsequently led to a variety of problems such as disguised unemployment, declining catch rate, diminishing returns, overfishing and juvenile fishing leading to depletion of fish stock as well as destruction of marine biota (Kurien, 1991; Kurien and Achari, 1994; Devaraj and Vivekanandan, 1999; Mathew, 2000). Further, continuous increase in energy requirements commensurates with escalating fishing efforts has proved to increase the carbon foot print of the sector during the past half a decade. A recent study has indicated that for every tonne of fish caught, the $\mathrm{CO}_{2}$ emission has increased from 0.50 tonnes to 1.02 tonnes during 1961 to 2010 (Vivekanadan et al., 2013). The negative externalities of such unsustainable intensification of fishing efforts have started getting manifested lately in the form of a declining trend in landings, after peaking at 3.9 Mt in 2012. Large-scale stock declines have been reported in case of certain commercially important fishes, such as sardine in the Kerala coast of India. Notably, sardine landings in Kerala coast plummeted from 1.58 lakh tonnes in 2014 to just about 0.46 lakh tonnes by 2016 (CMFRI, 2017). Similarly, several marine organisms such as elasmobranchs, marine mammals, seahorse and sea cucumbers have been classified under endangered/ vulnerable categories under Wildlife Protection Act, 1972. These facts underline the possible deepening of the vulnerabilities of coastal fisher folk in the near future, particularly the income and employment security of the small and marginal fishermen. Against this backdrop, this paper takes a look at the ways and means to improve efficiency of marine fishing in India, besides exploring potential avenues for enhancing incomes and diversifying the livelihood opportunities for a considerable section of small and marginal coastal fisher folk in the country.

\section{Marine Fisheries Sector in India: An Overview}

The marine fisheries sector provides employment to nearly 4 million people, comprising 8.64 lakh fishermen families inhabiting in 3,288 fishing villages along the east and west coasts of the Indian subcontinent. As per the Marine Fishery Census, 2010, about 61.1 per cent of coastal fisher folk were engaged in fishing and allied activities, of which about 38 per cent are active fisher folk. This includes about 7.9 lakh numbers of full-time fishermen and 1.35 lakh part-time fishermen apart from 0.64 lakh fish seed collectors. Among those involved in allied activities in the sector, 36.5 per cent were engaged in marketing of fish and 32.6 per cent were working as labourers (GoI, 2012). Apart from this, a significant number of coastal inhabitants find their livelihood in secondary and tertiary activities related to fishing such as post-harvest handling and processing of fish, activities related to craft and gear manufacturing, maintenance, supply of fishing equipment, transport and logistics and so on.

There are three obvious sub-sectors in marine fishery, generally classified based on type of propulsion, level of mechanization involved in fishing, type of fishing gears used and the resources targeted. The mechanized sub-sector that contributes to about 82 per cent of total landings is the dominant one that comprises 72,559 fishing crafts with an estimated value of capital investments to the tune of ₹ 20,810 crore (Table 1). The main types of mechanized crafts include trawlers, gillnetters, dolnetters, and liners that use mechanized means for operating the gears. About 33 per cent of active fishers are engaged in this sector. The motorized sub-sector engages the maximum number of active fishers (62\%) and mainly includes ring-seiners, purse-seiners and bag netters that contribute about 17 per cent to the total catch. The nonmotorized sector that predominantly defined marine fishing in India till the early-1990s, and now a minority, presently contributes hardly about 1 per cent of catch and engages about 5 per cent of the marine fishing workforce.

Fish landings that grew at a moderate pace during the 1960s and 1970s got a real fillip with motorization of indigenous fishing crafts during the mid-1980s. The number of vessels with out-board motors (OBM) grew exponentially during this period. Subsequently, the emergence of trawlers and other mechanized fishing vessels armed with improved fishing gears and communication and navigation devices transformed the sector from a subsistence level to one which handles multi-million dollar worth of fish catches every year. The widespread adoption of mechanized fishing towards late -1990 s using vessels equipped with better cold storage facilities enabled the fishermen to extend their operations from single day fishing to multi-day 
Table 1. An overview of marine fishery across its sub-sectors in India

\begin{tabular}{|c|c|c|c|}
\hline Particulars & Mechanized & Motorized & Non-motorized \\
\hline Main type of gears & $\begin{array}{l}\text { Trawlnet, Gillnet, Purse- } \\
\text { seine, Hook \& line }\end{array}$ & $\begin{array}{l}\text { Ring-seine, Purse-seine, } \\
\text { Boat-seine, Hook \& line, } \\
\text { Dolnet, Driftnet, Long line }\end{array}$ & $\begin{array}{l}\text { Hook \& line, Pole \& } \\
\text { line, Bagnet, Long line }\end{array}$ \\
\hline $\begin{array}{l}\text { Main resources } \\
\text { targeted }\end{array}$ & $\begin{array}{l}\text { Indian mackerel, Cephalopods, } \\
\text { Ribbon fishes, Penaeid prawns, } \\
\text { Priacanthus spp., Threadfin } \\
\text { breams, Croakers }\end{array}$ & $\begin{array}{l}\text { Oil sardine, Other sardines, } \\
\text { Tunas, Anchovies, Seer } \\
\text { fishes, Mullets }\end{array}$ & $\begin{array}{l}\text { Tunas, Oil sardine, } \\
\text { Other sardines, } \\
\text { Mullets }\end{array}$ \\
\hline $\begin{array}{l}\text { Contribution to total } \\
\text { landings }(\%)(2010)\end{array}$ & 82 & 17 & 1 \\
\hline $\begin{array}{l}\text { Number of fishing } \\
\text { crafts }(2010)\end{array}$ & 72,559 & 71,313 & 50,618 \\
\hline $\begin{array}{l}\text { Estimated value of } \\
\text { inventories (₹ crores) (2015) }\end{array}$ & $\begin{array}{l}20,810 \\
(92 \%)\end{array}$ & $\begin{array}{l}1,498 \\
(7 \%)\end{array}$ & $\begin{array}{l}354 \\
(1 \%)\end{array}$ \\
\hline $\begin{array}{l}\text { Active fishers engaged } \\
\text { (Nos. in lakhs) (2010) }\end{array}$ & $\begin{array}{c}3.27 \\
(33 \%)\end{array}$ & $\begin{array}{c}6.14 \\
(62 \%)\end{array}$ & $\begin{array}{l}0.49 \\
(5 \%)\end{array}$ \\
\hline
\end{tabular}

Sources: GoI (2012); CMFRI (2016)

fishing that ranges from 2-7 days or even longer (Ramachandran, 2004). This further boosted the capture fish production with landings peaking at $3.9 \mathrm{Mt}$ in the year 2012 (Figure 1). Thereafter, a dip in landings has been noticed in the subsequent years. Though the culture sector outpaced the marine capture sector in terms of growth in production over the years, the latter continues to occupy an undeniable position, contributing about 35 per cent to the total fish production from all sources (GoI, 2016). The main fishery resources landed in India include Indian mackerel, oil sardine, cephalopods, ribbon fishes, penaeid and non-penaeid prawns, Priacanthus spp., threadfin breams and croakers among other minor groups. Gujarat (21\%) was the largest contributor to total marine fish landings in 2016, closely followed by Tamil Nadu (20\%), Karnataka (15\%) and Kerala (14\%) (CMFRI, 2017). The marine fisheries is a

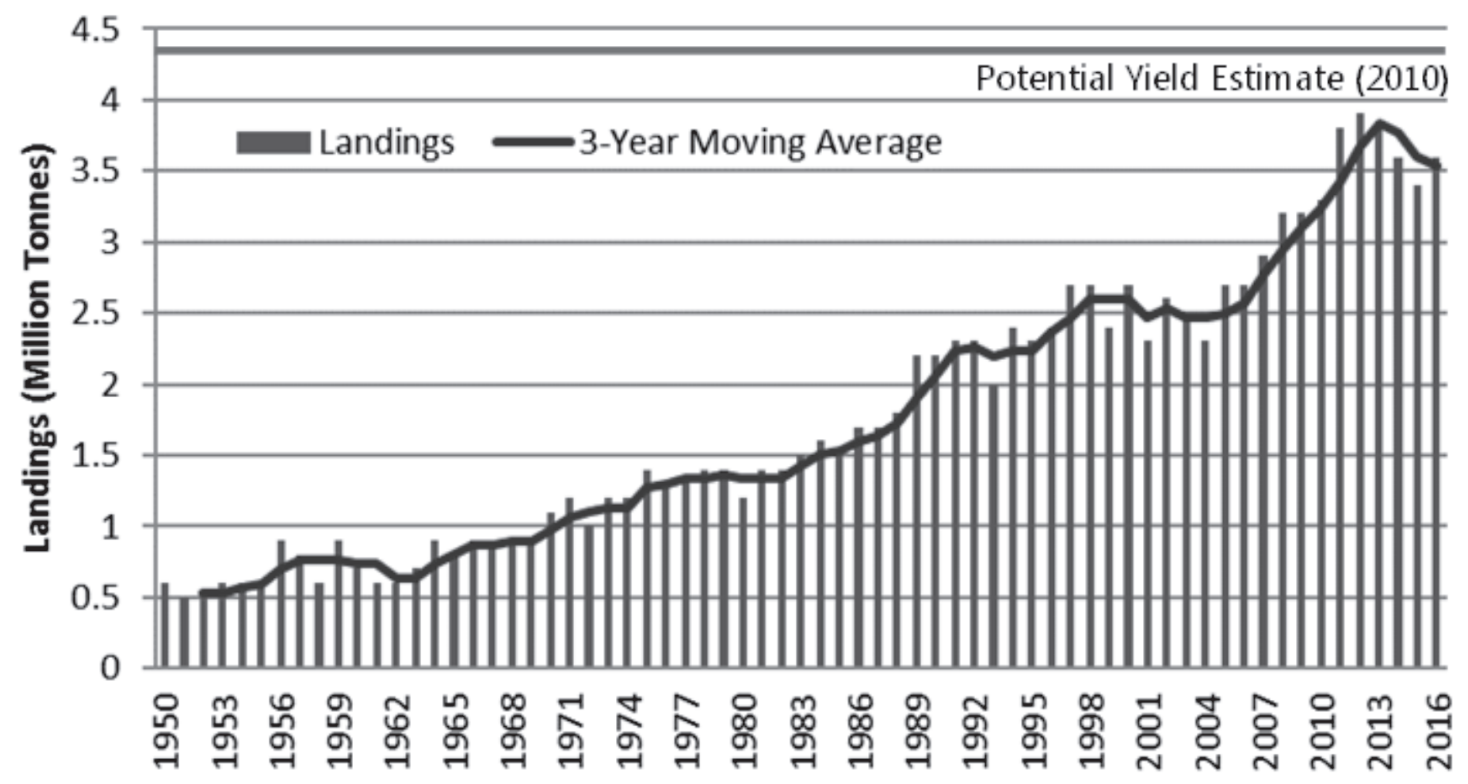

Figure 1. Marine fish landings in India: 1950-2016 
leading contributor to the foreign exchange earnings of the country through exports of fresh and frozen products, valued at ₹ 37,870.90 crore (USD 5.78 billion) in 2016-17 (MoC\&I, 2017).

\section{Income from Fishing: An Appraisal}

The above account on the profile of marine fishing in India provides a fair idea about the level of heterogeneity and complexities associated with the sector. The multiplicity of vessel and gear types, their varying catch capacities and efficiency levels, high level of variability associated with catches during routine operations, variability across seasons, heterogeneity in resources and the volatility in prices they command during different market conditions add to the perplexity of marine fishing. Consequently, it is quite difficult to arrive at a figure that represents income from marine fishing in realistic terms. Acknowledging these limitations, an attempt has been made to present the cost and earnings estimates associated with major craft gear combinations across the states in India for throwing light on the present income potential of the sector.

Table 2 presents the economics of single-day fishing with respect to a few selected craft-gear combinations in seven maritime states. They include mechanized trawl-net and motorized ring-seine in Kerala, non-motorized gillnet and motorized purseseine in Karnataka, mechanized trawl-net and motorize purse-seine in Maharashtra, mechanized trawl-net and gillnet in Tamil Nadu, motorized mini trawl-net and non-motorized gillnet in Andhra Pradesh as well as motorized gillnet and lowpin/highpin in Odisha. Strikingly, but quite in congruity with the above remarks, the estimates of net operating income and incomes of vessel crew varied widely across craft-gear categories and states. For instance, while the mechanized trawl-net and purse-seine operations in Maharashtra fetched as high as ₹ 51,575 and ₹ 50,333 respectively on an average, non-motorized gillnet operations in Andhra Pradesh returned only ₹ 729 per trip (Narayanakumar et al., 2016). Similarly, net operating incomes from motorized mini-trawl in Andhra Pradesh (₹ 867/trip) and mechanized gillnet in Gujarat (₹ 862/trip) were also among the lowest. The lay system of wage sharing (McConnel and Price, 2006) was followed in all the states under consideration wherein, the crew were remunerated with a share of

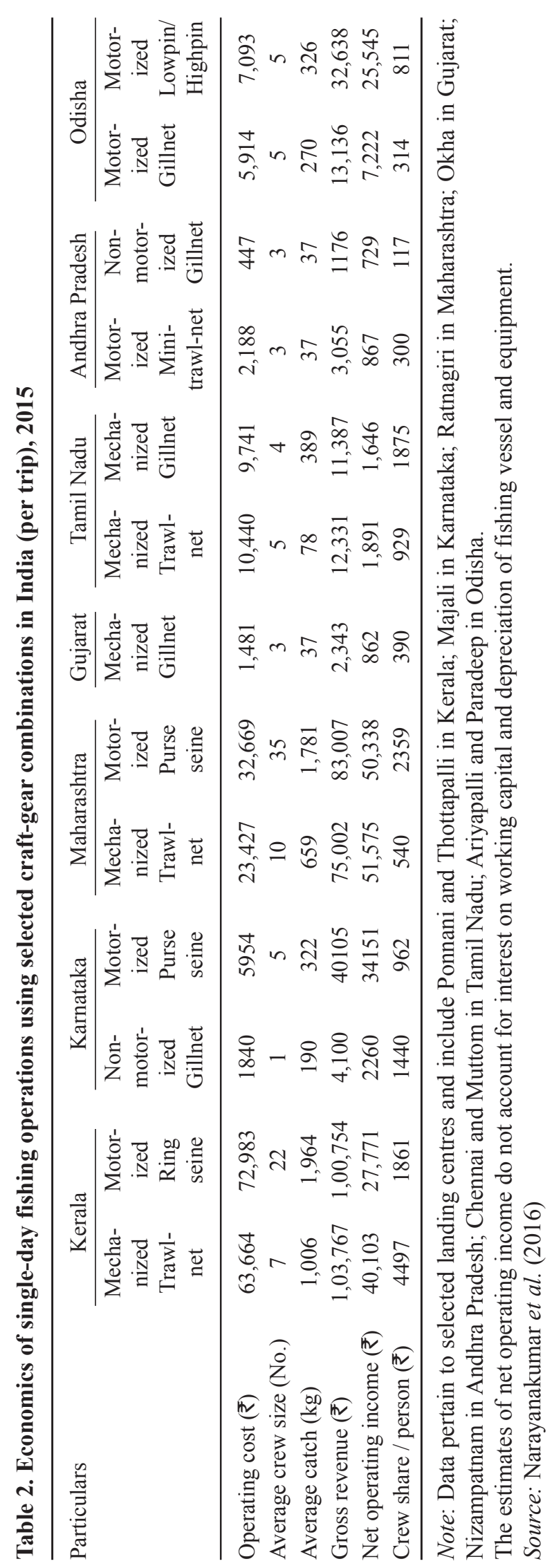


revenues or share of revenues less costs. Nevertheless, high level of variability in shares was noticed across regions with the highest in Tamil Nadu (60-75\% of gross revenue) and Kerala (50-60\%) and the least in Odisha (12-20\%). Accordingly, the estimated crew share per person also varied considerably, and was the highest ( $₹ 4,497 /$ trip) for mechanized trawl operations in Kerala, followed by motorized purse-seining in Maharashtra. On the other hand, the income earned by a crew member in non-motorized gillnet in Andhra Pradesh was quite meager at ₹ 117 /trip on an average. The crew wages of motorized mini-trawler in Andhra Pradesh (₹300/trip), motorized gillnet in Odisha (₹ 314/ trip) and mechanized gillnet in Gujarat ( $₹ 390 /$ trip) were also quite low and indicated the vulnerability of the labour force depended on these vessels for livelihood.

A similar account on incomes from various craftgear combinations engaged in multi-day fishing operations (2-5 days) for the selected states is presented in Table 3. Compared to single-day operations, the operating costs, gross revenue and net operating incomes were obviously higher in most cases considered. The highest net operating income was observed in the case of multi-day trawl fishing in Kerala with an average estimate of ₹ 3,48,016/trip of 2-5 days. This was followed by mechanized trawl fishing in Maharashtra (₹ 1,84,126/trip) and Karnataka (₹ 1,71,315). Among all, the least net income was earned by motorized hook and line fishing in Odisha with an average of ₹ 498/trip. The craft-gear combinations such as mechanized purse-seine in Maharashtra, mechanized gillnet in Gujarat and Andhra Pradesh yielded modest net incomes ranging from $₹ 11,000$ to $₹ 16,000$ per trip. The crew share per person was the highest from mechanized gillnetting in Gujarat (₹ 19,055), closely followed by mechanized trawling in Kerala (₹ 18,733) and Karnataka (₹ 17,982).

Several insights can be drawn from the above assessment of income from fishing. Methods such as mechanized trawling, gillnetting, purse-seining and motorized lowpin/highpin were found to yield impressive returns, both for the boat owners and the crew. However, there were several other cases, particularly under motorized and non-motorized sectors, that yielded modest incomes that support only subsistence levels of living. Nearly 67 per cent of active fishers belong to the non-mechanized sector and a majority of them operate under subsistence level.
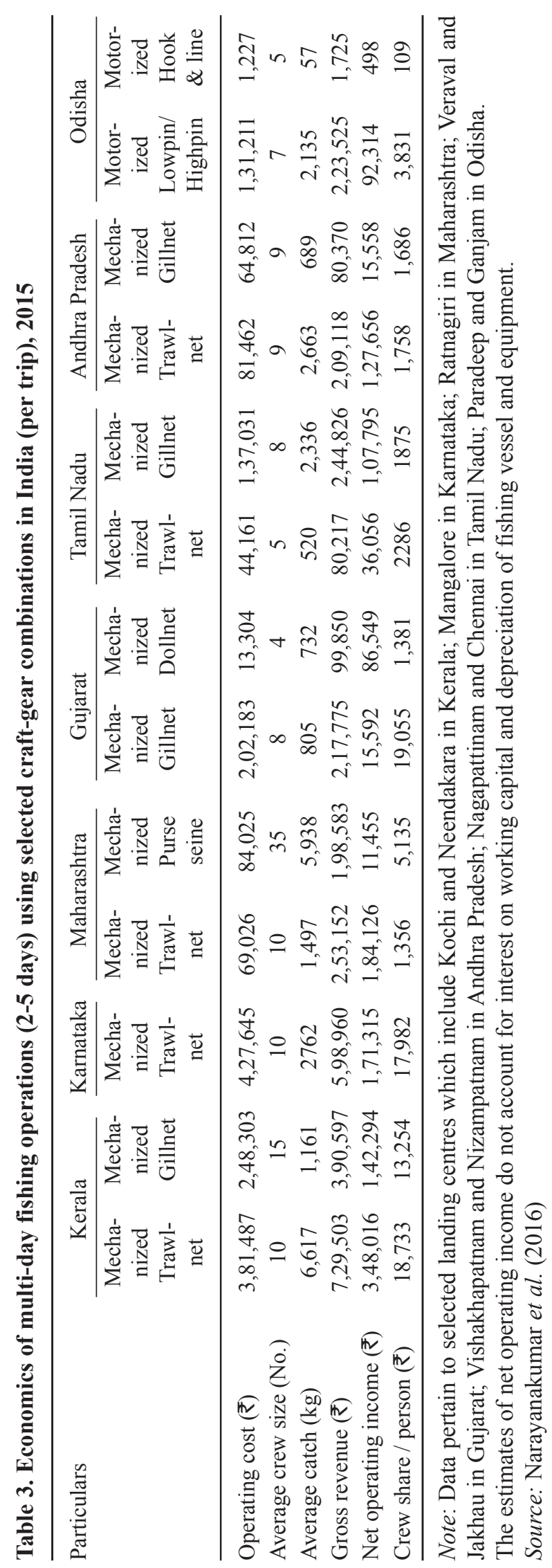
Further, per trip incomes, as outlined above, give only partial understanding of the earnings of a fisherman. This is because, fishing in the sea depends a lot on factors such as weather conditions, season of fishing, stock of major fishes and so on. The number of actual fishing days for a mechanized fishing boat generally ranges from 200 to 250 days a year, after taking due account of closed seasons, off seasons, period of maintenance of vessel and gear, religious holidays, etc. (Najmudeen and Sathiadhas, 2007; Geetha et al., 2014). Certain vessels such as mechanized purse seine boats fish only for 90-120 days a year. Even in the case of non-motorized vessels, the maximum number of fishing days is limited to 250-280 days (Sathiadhas, 1997). Therefore, the average per day income of a fisher is much lower than what the above estimates connote. Moreover, to consider income as the foremost variable that determines the standard of living of a fisherman would be misleading. Unlike in many other sectors, fishermen face high level of vulnerabilities in their dayto-day life. Being coastal dwellers, fishermen are highly exposed to the vagaries of extreme climatic events which add to the risks associated with their routine fishing activities. Further, ownership of productive assets such as land and livestock is comparatively lower among fishermen living in most of the coastal settlements. Therefore, the majority of fishermen live with perpetual income vulnerability with little opportunities to generate supplementary income through any alternative source. It is, therefore, worthwhile to ponder over the options that could either enhance incomes through fishing or explore alternative livelihoods that could be supported by limited resources within the coastal environments.

\section{Exploring Opportunities to Enhance Incomes of Fisher Folk}

\section{Harnessing Untapped Resources}

Oceanic waters of the Indian EEZ remain underexploited and offer considerable scope for enhancing production through targeted exploitation of large pelagics such as tunas, barracudas, rainbow runners, billfishes, pelagic sharks and oceanic squid of high commercial importance. The total potential yield of oceanic tuna and allied species in the Indian EEZ is estimated to be 2.08 lakh tonnes, comprising 0.8 lakh tonnes of yellow fin tuna, 0.99 lakh tonnes of skipjack tuna, 0.21 lakh tonnes of pelagic sharks and the rest made up by other species such as big eye tuna, bill fishes, barracudas, dolphin fish and wahoo (DADF, 2011). An Earlier study pegged the total potential of oceanic squids at 0.20 lakh tonnes to 0.50 lakh tonnes (Silas et al., 1986). Sustainable exploitation of these resources can considerably augment the income opportunities of fishermen if they are sufficiently empowered to do so. New initiatives are required at both policy and governance levels to bring about perceivable changes, which include: (i) ensuring government support for development and deployment of deep sea fishing vessels, (ii) training the prospective entrepreneurs and fishermen on deep sea fishing methods and techniques, (iii) framing a national deep sea fishing policy that clearly lays down the contours and approaches to tap the deep sea resources and potential beneficiary groups, and (iv) developing adequate logistic and market support for deep sea fishing fleet thus developed.

Recreation fishing, also called sport fishing, constitutes a billion-dollar industry world-wide, with countries such as Sweden depending on it even more than commercial fishery. The lack of scientiûc knowledge on the basic biology of sport fish species, targeting of threatened species, and the absence of region- or species-specific angling regulations for recreational ûsheries are identified as some of the challenges associated with this sector in India. With organized governance structure, better legislative support and a clear policy framework, developing a responsible and sustainable recreational fisheries industry in India is possible and has considerable potential for augmenting incomes of fisher folk (Gupta et al., 2015). The concept may be integrated with aquatourism initiatives already being taken up in many maritime states.

\section{Enhancing Efficiency of Fishing Fleet}

Enhancing the efficiency of existing fishing fleet through suitable conversion and up-gradation together with introduction of improved crafts and gears could prove to be a way forward to bring about profitable and responsible fishing in marine waters. Low-cost fuel-efficient and solar power-operated fishing vessels designed and developed by ICAR-CIFT together with improved fishing gears such as juvenile excluder, semipelagic trawl system, short-body shrimp trawl and cutaway top belly shrimp trawl could help the fishers in 
efficient use of inputs and thereby cut costs. These technologies also help in selective harvesting that minimizes juvenile fishing and by-catch (Boopendranath, 2012). The suitability of these technologies at various coastal regions and their adaptability with respect to alternative fishing methods need to be studied through multi-location trials and demonstrations. Further, successful technologies could be popularized through strong extension drives together with financial assistance programmes targeting small and marginal fishermen.

\section{Use of Space Technology and ICT}

Recent advancements, particularly in the field of space science and information technology can be effectively utilized for improving the efficiency of fishing in India, thereby driving up incomes of the fishermen. One such promising intervention includes dissemination of potential fishing zone (PFZ) advisories to the fishermen. The portal,m@krishi launched by CMFRI in partnership with INCOIS, Hyderabad and Tata Consultancy Service (TCS) for the fishermen of Maharashtra is an excellent example which can be emulated in this milieu. Based on a survey conducted by the CMFRI at Maharashtra coast, it is estimated that adoption of m@krishi service has resulted in 30-40 per cent increase in fish catch and 30 per cent saving in fuel costs (Singh and Singh, 2016). Another recent study by George et al. (2011) in Andaman and Nicobar islands for selected craft types has indicated increase in fishing revenues by $40-50$ per cent through adoption of PFZ advisories. Similarly, measures such as spatial planning of marine and coastal habitats covering major fishing grounds using advanced GIS mapping tools as well as setting up of vessel monitoring system (VMS) could ensure efficient fishing operations besides warranting fool proof monitoring, controlling and surveillance (MCS) as well as enhanced security across the coastline.

\section{Mariculture}

Mariculture, i.e., culture of marine organisms under controlled conditions in sea, has immense potential to meet the growing demand for fish. Some of the promising mariculture options include open sea cage farming, sea weed farming, integrated multi-tropic aquaculture (IMTA), mussel and oyster culture, ornamental fish production and pearl culture.
Unfortunately, the lack of a proper mariculture policy is a major lacuna to enhance mariculture ventures such as sea cage farming in the country. It is anticipated that with the availability of favourable policy guidelines for utilization of coastal waters and increased private investments, the enterprise would expand further in the coming days. The areas of focus include development of a leasing policy, demarcation of potential mariculture sites along Indian coasts on a GIS platform, measures to strengthen seed and feed supply for mariculture ventures, guidelines for development of infrastructure and value chains for brood stock management, and large scale seed production of prospective fish and shell fish species (George et al., 2017). Some of the promising mariculture ventures that have considerable potential to augment income of coastal fisher folk are elaborated below.

\section{Open Sea Cage Farming}

Open sea cage farming is a promising venture for prospective entrepreneurs to realize high net returns through culture of high-value marine fish species in the open sea. CMFRI is the pioneer to initiate this technique in India by demonstrating open sea farming of several fish species such as cobia, pompano, grouper, sea bass, etc. Two different versions of indigenously fabricated $6 \mathrm{~m}$ diameter cages (made of Galvanized Iron (GI) and High Density Poly Ethylene (HDPE)) have been developed by the institute. On an average, 2-4 tonnes of fish can be produced in a $6 \mathrm{~m}$ diameter cage per cycle. The net economic return per crop ranges from ₹ 1.5 lakh to ₹ 4.0 lakh, depending on the species grown (Gopalakrishnan et al., 2017). The indicative economics of sea bass and cobia in open sea as well as brackishwater cages in Kerala and Goa are presented for better understanding in Table 4. With successful demonstrations along the maritime states, cage farming has started gaining momentum in various states of India. Several farmer groups and development agencies in the coastal regions are actively contemplating to take up cage farming in the near future.

\section{Seaweed Farming}

Seaweeds have a large number of applications including food for human consumption or as a source of hydrocolloids such as agar and carrageenan processed into food additives, pet food, feeds, fertilizers, biofuel, cosmetics and medicines, among 
Table 4. Indicative economics of fin fish farming in sea cages / brackish water cages in India, 2016

\begin{tabular}{|c|c|c|c|}
\hline \multirow[t]{2}{*}{ Particulars } & \multicolumn{2}{|c|}{$\begin{array}{c}\text { Goa } \\
\text { (Sea cage of } 6 \mathrm{~m} \text { diameter } \\
\text { and } 4 \mathrm{~m} \text { depth) }\end{array}$} & \multirow{2}{*}{$\begin{array}{c}\begin{array}{c}\text { Kerala } \\
\text { (brackish water }\end{array} \\
\text { cage of } 8 \mathrm{~m} \times 4 \mathrm{~m} \times 4 \mathrm{~m} \text { ) } \\
\text { Sea bass }\end{array}$} \\
\hline & Sea bass & Cobia & \\
\hline \multicolumn{4}{|c|}{ Capital expenditure (in ₹) } \\
\hline Cage structure (GI pipe, including nets) & $1,10,000$ & $1,10,000$ & 60,000 \\
\hline Expenses on mooring & 15,000 & 15,000 & 10,000 \\
\hline Other fixed expenses (refrigerator, containers, etc.) & 25,000 & 25,000 & 15,000 \\
\hline Gross fixed cost & $1,50,000$ & $1,50,000$ & 85,000 \\
\hline \multicolumn{4}{|c|}{ Operational expenditure (in ₹) } \\
\hline Seed cost & 65,000 & 50,000 & 40,000 \\
\hline Feed cost & 90,000 & $1,30,500$ & $1,50,000$ \\
\hline Labour charges & 36,000 & 36,000 & 3,6000 \\
\hline Harvesting charges & 10,000 & 10,000 & 8,000 \\
\hline Boat hire and fuel charges & 30,000 & 30,000 & - \\
\hline Interest on fixed capital (12\%) & 18,000 & 18,000 & 10,200 \\
\hline Annual depreciation (20\%) & 27,000 & 27,000 & 25,000 \\
\hline Miscellaneous expenditure & 10,000 & 10,000 & 10,000 \\
\hline Gross operating cost & $2,86,000$ & $3,11,500$ & $2,79,200$ \\
\hline \multicolumn{4}{|c|}{ Revenue and net income (in ₹) } \\
\hline Gross revenue & $7,00,000$ & $6,00,000$ & $4,00,000$ \\
\hline Net operating income & $4,14,000$ & $2,88,500$ & $1,20,800$ \\
\hline B:C Ratio & 2.44 & 1.92 & 1.43 \\
\hline
\end{tabular}

Notes

Sea bass at Goa: Seed cost: ₹ 32.50/seed for 2000 seeds; Feed cost: ₹ 22,500 for pellet feed and ₹ 67500 for sardine feed (FCR: 1:2); Labour charges: ₹ 150/day for one person for 8 months. Interest: $12 \%$ per annum; Depreciation: 20\% per annum; Gross revenue: ₹ 350/kg for 2 tonnes of harvest.

Cobia at Goa: Seed cost: ₹ 50/seed for 1000 seeds; Feed cost: ₹ 22,500 for pellet feed and ₹ 1,08000 for sardine feed (FCR: 1:6); Gross revenue: ₹ 300/kg for 2 tonnes of harvest; Other calculations same as above.

Sea bass at Kerala: Seed cost: ₹ 40/seed for 1000 seeds; Feed cost: ₹ 1,50,000 for sardine feed (FCR: 1:2); Gross revenue: ₹ 350/kg for 1.1 tonnes of harvest; Other calculations same as above.

Source: Computed by authors.

others (McHugh, 2003). Red seaweed species such as Kappaphycus and Eucheuma are presently cultivated in more than 20 countries, of which major producers are Canada, Philippines, Indonesia, Tanzania, and Vietnam (Bindu and Levine, 2011). Sea weed farming is a relatively simple technology requiring low capital investment with high potential to improve socioeconomic conditions of marginalized coastal population (Trono et al, 1980). Culture of sea weeds has shown to increase food security in the farming villages as their revenue earning potential is greater than that of alternative agricultural enterprises (Beveridge et al., 2010; Gupta, 2010).
Sea weed farming has picked up as an economically viable farming practice over the past two decades on the shores of Palk Bay, Tamil Nadu. A floating system of $3 \times 3 \mathrm{~m}$ rafts with a 45 - day farming cycle for a total of 270 production days per year is being practised by the self-help groups (SHG) in the region (Valderrama et al., 2015). Considered as one among the most environmentally benign activity, it has considerable potential to augment the livelihoods of coastal dwellers in the country. The economics of sea weed farming in Palk Bay region as reported by a recent study (Johnson et al., 2017) is presented in Table 5. A 
Table 5. Cost and returns per cycle of seaweed cultivation (45 rafts, one raft / day), Tamil Nadu

\begin{tabular}{lccc}
\hline Particulars & $\begin{array}{c}2011 \\
(6 \text { cycle })\end{array}$ & $\begin{array}{c}2012 \\
(6 \text { cycle })\end{array}$ & $\begin{array}{c}2013 \\
\text { (4 cycle) }\end{array}$ \\
\hline Annual dried seaweed production $(\mathrm{kg})(20 \mathrm{~kg} /$ raft $)$ & 5400 & 5400 & 3600 \\
Price of dried seaweed (₹/kg) & 18 & 22 & 25 \\
Annual revenue (₹) & 97,200 & $1,18,800$ & 90,000 \\
Annual costs (₹) & 47,400 & 38,650 & 31,350 \\
Annual net Profit (₹) & 49,800 & 80,150 & 58,650 \\
Profit margin (\%) & 51 & 67 & 65 \\
Break-even price (₹) & 9 & 7 & 9 \\
\hline
\end{tabular}

Source: Johnson et al. (2017)

feasibility study conducted in the sea water inundated areas in South Andamans has revealed that these regions have huge potential for the enterprise (Gopalakrishnan et al., 2017). Similar studies need to be conducted in other suitable areas for enabling further spread of this promising livelihood activity.

Another innovative farming concept in this context is integrated multi-tropic aquaculture (IMTA), introduced by CMFRI, wherein appropriate proportions of fin fishes/shrimp with shell/herbivorous fish can be integrated with sea weed farming. IMTA can mitigate the potential negative externalities of sea cage farming with simultaneous enhancement in seaweed yield. This technique has proven to enhance sea weed yield by about $110 \mathrm{~kg}$ per cycle with commensurate income enhancement. The technology is currently adopted by 100 farmers in Palk Bay region (Gopalakrishnan et al., 2017).

\section{Other Promising Mariculture Ventures}

Mussel and oyster culture has gradually spread across the backwater belts of Kerala, Karnataka, Goa and Maharashtra owing to their high profitability. A number of methods such as stake culture, on-bottom culture, long-line culture, raft culture, rack culture, etc. are followed for mussel and oyster farming. Over 1000 farmers are practising rack culture of green mussel in the Padanna estuary areas in Kasargod, which is contributing three-fourths of green mussel production in India (Mohammed, 2015). A net return of about ₹ 88,000 per unit of 200 seeded strings can be obtained through rack method of green mussel farming in this region (Table 6). Though technology for mussel and oyster farming is fairly well available, what is lacking is the adequate marketing and processing infrastructure (George et al., 2017). Other promising mariculture avenues include ornamental fish farming and pearl culture for which technology has been perfected by now. More number of entrepreneurs may be encouraged to take up these ventures by providing technological, financial, marketing as well as logistical support.

\section{Holistic Development of Marine Fish Value Chains}

Value chains play a more important role than farm management in ensuring profitability of an enterprise in the field of agriculture and allied sector. A wide array of value chain development interventions can be initiated in the marine fisheries sector so that the fish and fishery products reach the consumer in good quality. Considerable investment needs to be pumped in to modernize cold chains in fishing boats as well as along main links in the value chain including reefers, small retail outlets, retail carrier vehicles, small scale fish handling and processing units.

Quality control of marketed fish is another major concern in the context of strengthening value chains. In recent times, concerns have been raised from various quarters over the quality of fish marketed. With rapid increase in fish demand unmatched by domestic catch, widespread use of unauthorized preservatives and other harmful chemicals has been reported across the country. In this context, it would be promising to set up fish quality certification units in every major harbour/fish landing centre/wholesale market so that not only the fish landed but also which are transported from other 
Table 6. Indicative economics of rack method of green mussel farming in Padanna, Kerala, 2016

\begin{tabular}{|c|c|c|}
\hline Expenditure head & Details of expenditure for a rack of 200 seeded strings & $\begin{array}{l}\text { Amount } \\
\text { (₹) }\end{array}$ \\
\hline \multicolumn{3}{|c|}{ Fixed expenditure } \\
\hline Rack construction (Poles and rope) & 20 bamboo poles@ of ₹ 300/pole; 4 kg of 3-4 mm rope @ ₹ 250 / kg & 7,000 \\
\hline Labour charges for rack construction & 4 male labourers@ @ 750/person & 3,000 \\
\hline Gross fixed expenditure & & 10,000 \\
\hline \multicolumn{3}{|c|}{ Operational expenditure } \\
\hline Seed cost & 200 kg of seeds@ @ 50/kg & 10,000 \\
\hline Associated costs in stocking & Cloth, rope, coir, etc. & 5,500 \\
\hline Labour charges for stocking & 8 female labourers@ @ 400 / person & 3,200 \\
\hline Rack maintenance charges & 5 man-days@ @ 750/man-day & 3,750 \\
\hline Harvesting charges & 2 male labourers@₹750/person & 1,500 \\
\hline Miscellaneous & Hiring of canoe, etc. & 2,550 \\
\hline Interest on fixed cost & $12 \%$ per annum & 1,200 \\
\hline Depreciation & $33.3 \%$ per annum & 3,300 \\
\hline Gross operational expenditure & & 31,000 \\
\hline \multicolumn{3}{|c|}{ Revenue and Net income } \\
\hline Gross revenue & Total harvest of 1.4 tonnes / rack (@ 7 kg/string) valued at ₹ 85/kg & $1,19,000$ \\
\hline Net operating income & & 88,000 \\
\hline B:C Ratio & & 3.83 \\
\hline
\end{tabular}

Source: Computed by authors

markets are adequately checked for the presence of harmful preservatives. The technologies and detection kits developed by the Central Institute of Fisheries Technology (CIFT), Kochi, can be utilized for this purpose.

Ecological certification of selected fisheries for green/sustainable fishing activities is another important intervention that has the potential to enhance value of fish marketed, so that more entrepreneurs can be mobilized for mariculture activities. Specific fisheries, particularly mariculture ventures, along the coast can be selected for certification so that the fishermen/fish farmers associated with them can be benefitted with premium prices realized at global/ high-end domestic markets. MSC certification of Ashtamudi short neck clam facilitated by CMFRI is an example worth emulating in this regard (Mohammed, 2016).

\section{Conclusions}

The marine fishery sector continues to be the lifeline of a significant number of impoverished and vulnerable coastal inhabitants, who have limited alternative livelihood options and minimal productive assets. This paper has presented a set of alternative strategies and options that have the potential to enhance the incomes of India's coastal fisher folk. Expanding the contours of fishing to sustainably exploit the untapped deep sea and non-conventional resources is proposed to be an important course of action to throw new opportunities to enterprising fishermen. Similarly, improving the efficiency of fishing through modernization/technological up-gradation of fishing fleet/gears as well as harnessing the latest developments in space and ICT would pay rich dividends through enhanced incomes. Another prospective strategy would be to broad-base the alternative livelihood sources of coastal dwellers by harnessing the potential of mariculture avenues such as open sea cage farming, seaweed farming, IMTA, mussel and oyster culture, ornamental fish farming and pearl culture. Given the role of efficient value chains in ensuring a larger share of incomes for the primary producers, i.e., fishermen, holistic development of fish value chains through strengthening the cold chains, quality control of marketed fish and ecological certification of 
mariculture ventures is also suggested. The sustainable enhancement in incomes of the costal fishermen could certainly play a key role in ensuring a thriving coastal economy that contributes to meet the future demand for fish and fishery products in the country.

\section{References}

Bavinck, M. and Johnson, D. (2008) Handling the Legacy of Blue Revolution in India - Social Justice and SmallScale Fisheries in a Negative Growth Scenario. American Fisheries Society Symposium, 49: 585-599.

Beveridge, M.M., Dungan, P.P. and Brummet, R. (2010) Barriers to Aquaculture Development as a Pathway to Poverty Alleviation and Food Security: Policy Coherence and Responsibilities of Development Agencies. OECD Workshop, Paris, 12-16 April. Retreieved from http://www.oecd.org/greengrowth/ fisheries/45035203.pdf.

Bindu, M.S. and Levine, I.A. (2011) The commercial red seaweed Kappaphycus alvarezii - A case study at Vizhinjam village, Kerala, India. Journal of Applied Phycology, 23 (3): 321-335.

Boopendranath, M.R. (2012) Waste minimization in fishing operations. Fishery Technology, 49: 109-119.

CMFRI (ICAR-Central Marine Fisheries Research Institute) (2016) Annual Report 2015-16. Kochi.

CMFRI (ICAR-Central Marine Fisheries Research Institute) (2017) Marine Fish Landings in India 2016. FRAD Technical Report. Kochi.

DADF (Department of Animal Husbandry Dairying and Fisheries) (2011) Report of the Working Group for Revalidating the Potential of Fishery Resources in the Indian Exclusive Economic Zone. Ministry of Agriculture, New Delhi.

Devaraj, M. and Vivekanandan, E. (1999) Marine capture fisheries of India: Challenges and Opportunities. Current Science, 76 (3): 314-332.

Geetha R., Narayanakumar, R., Salim, S.S., Aswathy, N., Chandrasekhar, S., Raghavan, S.V. and Divipala, I. (2014) Economic efficiency of mechanized fishing in Tamil Nadu - A case study in Chennai. Indian Journal of Fisheries, 61(4): 31-35.

Gentry, R.R., Froehlich, H.E., Grimm, D., Kareiva, P., Parke, M., Rust, M., Gaines, S.D. and Halpern, B.S. (2017) Mapping the global potential for marine aquaculture. Nature Ecology and Evolution, 1: 1317-1324.

George, G., Krishnan, P., Sarma, K., Kirubasankar, R., Bharathi, M.P.G., Kaliyamoorthy, M., Krishnamurthy,
V. and Kumar, T.S. (2011) Integrated potential fishing zone forecasts: a promising information and communication tool for promotion of green fishing islands. Indian Journal of Agricultural Economics, 66 (3): 513-519.

George, G., Parappurathu, S., Ignatius, B., Abdussamad, E.M., Narayanakumar, R. and Gopalakrishnan, A. (2017) Sustainable Marine Capture Fisheries and Exploiting Untapped Potential in India, NABARD National Consultation Meet on Fisheries Policy, 24-25 April, Kochi.

Gopalakrishnan, A., Ignatius, B. and George, G. (2017) India's largest fisheries research body turns $70-$ CMFRI's legacy and few recent achievements. Fishing Chimes, 37(1): 38-44.

GoI (Government of India) (2012) Marine Fisheries Census 2010 Part I. The Department of Animal Husbandry Dairying and Fisheries, Ministry of Agriculture, New Delhi and Central Marine Fisheries Research Institute, Kochi.

GoI (Government of India) (2016) Pocket Book of Agricultural Statistics 2016. Directorate of Economics and Statistics, Ministry of Agriculture and Farmers Welfare, New Delhi.

Gupta, M. (2010) Enhancing the contribution of aquaculture to poverty alleviation, food security and rural development. Global Conference on Aquaculture 2010 Podcasts. Food and Agriculture Organization of the United Nations, Thai Department of Fisheries, and Network Aquaculture Centres in Asia-Pacific. Podcast retrieved from http://www.enaca.org/modules/podcast/ soundtrack.php?soundtrack_id=43.

Gupta, N., Bower, S.D., Raghavan, R., Danylchuk, A.K. and Cooke, S.J. (2015) Status of recreational fisheries in India: Development, Issues and Opportunities. Reviews in Fisheries and Aquaculture, 23: 291-301.

Johnson, B., Narayanakumar, R. Abdul Nazar, A.K., Kaladharan, P. and Gopakumar, G. (2017) An economic analysis of farming and collection of seaweed in Tamil Nadu coast. Indian Journal of Fisheries (forthcoming).

Kurien, J. (1991) Ruining the Commons and Responses of the Commoners: Coastal Overfishing and Fishermen's Actions in Kerala State, India. United Nations Research Institute for Social Development, Geneva, Switzerland.

Kurien, J. and Achari, T. R. T. (1994) Overfishing the coastal commons: Causes and consequences. In: Social Ecology, (Ed.) R. Guha, Oxford University Press, Delhi. pp. 218-244. 
Mathew, S. (2000) Gujarat fisheries: Time to move from exploitative to conservation and management regime. Workshop on Current Situation in Fisheries Sector in Gujarat. Gujarat Institute of Development Research, Ahmedabad.

MoC\&I (Ministry of Commerce and Industry) (2017) Press Release, Government of India, New Delhi.

McConnel, K.E. and Price, M. (2006) The lay system in commercial fisheries: Origin and Implications. Journal of Environmental Economics and Management, 51: 295-307.

McHugh, D.J. (2003) A Guide to Seaweed Industry. FAO Fisheries Technical Paper No. 441, Food and Agriculture Organization of the United Nations, Rome.

Mohammed, K.S. (2015) Mussel farming and its potential in India, In: Advances in Marine and Brackishwater Aquaculture, Eds: S. Perumal, A.R. Thirunavukkarasu, and P. Pachiappan. Springer India.

Mohammed, K.S. (2016) Conservation of marine fishery resources through eco-labeling in India, In: Marine Biodiversity and Bio prospecting for Sustainable Livelihood. Eds: Joseph, A. and Philip, R. Cochin University of Science and Technology, Kochi and University Grants Commission, New Delhi. 123 p.

Najmudeen, T.M. and Sathiadhas, R. (2007) Economic efficiency of input utilization of mechanized trawlers along the Kerala coast. Journal of Marine Biological Association of India, 49 (2): 113-117.

Narayanakumar, R., Salim S.S., Aswathy, N. and Sathianandan, T.V. (2016) A Study on the Estimation of Input Cost of Marine Fishery (Including Prawn and High-valued Fish) for Arriving at Gross Value Added (GVA). Technical Report submitted to the Ministry of
Statistics and Programme Implementation, Government of India.

Ramachandran, C. (2004) Teaching Not to Fi(ni)sh: A constructivist Perspective on Reinventing a Responsible Marine Fisheries Extension System. Central Marine Fisheries Research Institute, Kochi.

Sathiadhas, R. (1997) Production and Marketing Management of Marine Fisheries in India. Daya Publishing House, Delhi.

Singh, V.V. and Singh, D.K. (2016) m@KRISHI Fisheries - A blue ocean innovation, Marine Fisheries Information Service, 230: 3-6.

Silas, E.G., 1986. Cephalopod resources prospective, priorities and targets for 2000 A.D. Cephalopod bionomics, fisheries and resources of EEZ of India, Bulletin of Central Marine Fisheries Research Institute, 37:172-183.

Trono, G.C., Rabanal, H.R. and Santika, I. (1980) Seaweed Farming. FAO/UNDP South China Sea Fisheries Development and Coordinating Programme, SCS/80/ WP/91, Manila, Philippines.

Valderrama, D., Cai, J., Hishamunda, N., Ridler, N., Neish, I.C., Hurtado, A.Q., Msuya, F.E., Krishnan, M., Narayanakumar, R., Kronen, M., Robledo, D., GascaLeyva, E. and Fraga, J. (2015) The economics of Kappaphycus seaweed cultivation in developing countries: A comparative analysis of farming systems. Journal of Aquaculture Economics and Management, 19: $251-277$.

Vivekanandan, E., Singh, V.V. and Kizhakudan, J.K. (2013) Carbon footprint by marine fishing boats of India. Current Science, 105 (3): 361-366. 